\title{
Significance of Supplier Selection Criteria Evolvement in IT Outsourcing to Emerging Economies - Lessons from a Global IT Outsourcing Project
}

\author{
Harri Hyvonen \\ Outotec, Finland, University of Jyvaskyla, Finland \\ Mikko Helminen \\ Outotec, Finland \\ Chihiro Watanabe \\ University of Jyvaskyla, Finland \\ International Institute for Applied Systems Analysis (IIASA), Austria
}

\begin{abstract}
In line with the increasing significance of the acceleration of information technology (IT) advancement and also of harnessing the vigor of emerging economies, IT outsourcing to emerging economies has become global concerns. This enables global companies to enjoy a critical competitive edge by choosing the best option in outsourcing strategy and supplier selection. Consequently, supplier selection criteria have become critical issues for both suppliers and customers.

This paper attempts to provide insightful suggestions to these issues. An empirical analysis was conducted taking supplier selection criteria evolvement in global IT outsourcing project focusing on action research in a multinational company.
\end{abstract}

Noteworthy findings include impacts of manager's change, identification of creative moment and weighting of supplier selection criteria.

Keywords: IT outsourcing, emerging economies, supplier selection criteria, project management, action research

\section{INTRODUCTION}

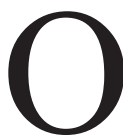

utsourcing to emerging global markets has been rapidly becoming popular in high-technology industry (Javalgi et al., 2009). This is particularly the case in information technology (IT) industry corresponding to the dramatic advancement of the Internet and cloud computing system (Zhao et al., 2013). With US driven global simultaneous stagnation in 20072008 and Europe's economic crisis emerged in 2010, established IT companies, particularly multinational companies look more to emerging markets for outsourcing partners (Grossler et al., 2013). Activating trend in the bottom of the pyramid, especially of the middle of the pyramid (Prahalad, 2004) accelerates this concern. Thus, IT outsourcing to emerging economies has become global concerns (Watanabe et al., 2014).

Journal of Technology Management for Growing Economies

Vol. 6, No. 2

October 2015 pp. 7-25

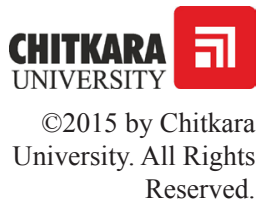


Hyvonen, H. Each economy, both developed and emerging, has unique economic, politiHelminen, M. cal, and socio-cultural issues that define institutional systems of respective Watanabe, C. countries (Hofstede, 1991). Successful outsourcing necessitates co-evolution between suppliers and customers by adapting respective institutional systems (Watanabe, 2009).

Under such circumstances, supplier selection criteria adapting institutional systems have become critical issues for both suppliers and customers for successful IT outsourcing, particularly to emerging economies. In order to correspond to this critical task, elucidation of IT outsourcing mechanism and conceptualization thereon would be essential.

IT outsourcing is widely studied as a general phenomenon during the last decades (Dibbern et al., 2004). Outsourcing, in its most basic form, can be conceived as the purchase of a good or service that was previously provided internally (Lacity and Hirschheim, 1993). Outsourcing agreements have normally long duration, require good governance and are strategic (Lacity and Willcocks, 1998, Levina and Ross, 2003, Teng et al., 2005). Outsourcing has been researched from several viewpoints in the literature (Lacity et al., 2009), like why organizations outsource, how companies benefit from IT outsourcing, what firms outsource and how firms measure the success (Dibbern et al., 2004). While the recent studies have developed around offshore and nearshore outsourcing, business process outsourcing and the provision of application services (Lacity et al., 2009, Rottman and Lacity, 2006), studies on outsourcing to emerging economies have been gaining special attention (Javalgi et al., 2009, Grossler et al., 2013).

The overall key theme for outsourcing studies during the last two decades has been how to leverage continuously expanding services market with significant business value (Lacity et al., 2008). During the last years, the cloud computing and related applications as a service, platform as a service and infrastructure as a service have been widely studied. Still the whole effect of cloud computing success and adoption is to be seen.

Since outsourcing is widely used in companies, most of the large companies have done or planning to continue outsourcing their IT or part of that (Palugod and Palugod, 2011). Already 96\% of large companies have outsourced part of their back office IT or support functions and $72 \%$ are going to increase significantly or moderately their outsourcing operating model (KPMG Stateof-Outsourcing, 2014). It is generally seen that only half of IT outsourcing projects succeed (The CIO Insight, 2012). Also only 44\% of the Finnish companies, which have recently carried out outsourcing projects, agree on that their results for outsourcing can be measured (TTL, 2013). When expectations

Journal of Technology Management for Growing Economies, Volume 6, Number 2, October 2015 
have not been met with realized results, relationship between supplier and customer has become challenging.

IT services outsourcing requires very different relationship between supplier and customer than earlier (Vagadia, 2012, Graf and Mudambi, 2005). The relationship management between the client and the supplier has been a common and challenging issue throughout the last decades (Hatonen, 2005, Lacity et al., 2009).

While outsourcing services can be managed easier as far as such services are located in one or few countries, complexity increases dramatically in global outsourcing particularly in emerging countries (Zhao et al., 2010). Furthermore, many executives believe that IT is evolving quickly into a utility and can be outsourced easily without defining the scope of outsourced services on adequate level (Lacity and Hirscheim, 1993). This deficiency leads easily over-optimistic expectations, which cause mistrust and damages between parties in outsourcing agreement and can lead in some cases to change of supplier or even back to in-sourced operating model.

Thus, outsourcing projects have several dimensions which need to be addressed i.e., technology, behavioral, financial, legal and strategic dimensions. If one of these dimensions fails, the whole project will fail.

In larger organizations, global presence and requirement to deliver standardized IT services significantly impact on outsourcing decisions. During decades, large IT companies like IBM, ICL, Hewlett-Packard and recently Indian companies such as TCS and HCL have built large outsourcing services. Global IT giants have operations both in developed and emerging countries and they can offer global customer capabilities to deliver centrally managed but locally delivered IT services which small local IT suppliers are unable to provide. Standard working method of those big service providers requires assimilating the staff of outsourced units into their culture (Kaplan and Norton, 2004). Cultural similarity between the service receiver and provider is no longer a critical predictor once participants experience their partners' organizational culture during the initial relationship period (Lee and Kim, 1999). The dominant IT suppliers influence the IT management's role by determining the range of technologies, solutions and services that are available within the organization. It is also recommended that in every outsourcing case both technical and legal experts should be involved (Lacity and Hirscheim, 1993).

In many cases, IT outsourcing project starts with target settings where achievable success factors are also defined and selected (Chou and Chou, 2009). These factors give good indications for defining criteria to be used in final vendor selection. Different criteria will represent certain vendor character

Journal of Technology Management for Growing Economies, Volume 6, Number 2, October 2015
Significance of Supplier

Selection 
Hyvonen, $\mathrm{H}$. Helminen, $\mathrm{M}$. Watanabe, $\mathrm{C}$. and they will get different weights to be used on comparing different vendors. While these indigenous nature of IT outsourcing initiated by large companies primarily to developed countries incorporate supportive suggestions to conceptualizing IT outsourcing mechanism adaptive to outsourcing to emerging economies, none has undertaken systematic conceptualization effort.

Given the significance of this conceptualization as an essential step for developing supplier selection criteria critical to IT outsourcing to emerging economies, this paper, on the basis of an empirical analysis on supplier selection criteria evolvement in global IT outsourcing, attempts to provide insightful suggestions to the foregoing conceptualization. Given the conceptualization objective, action research, instead of normal case study, is focused.

Taking advantage of authors' favorable position to test and apply forefront research method for a strategic outsourcing project in the multinational company for which authors are responsible, key outsourcing success factors were identified and evaluation criteria for vendor selection was created thereon. Then, impacts of the criteria on the project implementation were analyzed during the implementation period. In addition, initial criteria were tested after the project completion.

Section 2 explains action research and the research questions. Section 3 outlines analysis. Findings are demonstrated in Section 4. Implications to outsourcing to emerging economies are summarized in Section 5. Section 6 briefly summarizes noteworthy findings, policy implications and also the points for future works.

\section{ACTION RESEARCH AND THE RESEARCH QUESTIONS}

Action research is a research strategy for Information Systems (IS) studies providing first-hand experiences of IS theory in practice (Simonsen, 2009). Action research can be defined as "an iterative process involving researchers and practitioners acting together on a particular cycle of activities, including problem diagnosis, action intervention, and reflective learning" (Avison et al., 1999).

Simonsen (2009) has described risks related to action research in IS as follows:

(1) Action research is a very time-consuming way of producing empirical data and there is a high risk for the project not evolving as planned, which might lead to the failure of acquiring the anticipated empirical data.

(2) Action research is also personally demanding and challenging because it entails a close engagement with and commitment to collaborating industrial practitioners.

Mandatory to implement and empirical data collection was put the highest priority. Every experience/data was anticipated by empirical data. Authors'

Journal of Technology Management for Growing Economies, Volume 6, Number 2, October 2015 
engagement in the project from the beginning to the end was put the second priority. Whilst authors were responsible for the project, primary aim in the research was not only to analyze, understand, and interpret but also to improve and solve problems relevant to practice. As challenges in outsourcing project still remained low success rate (The CIO Insight, 2012), generalize IT outsourcing projects to achieve easier targets in coming projects was endeavored. This can be done through better understanding of evaluating service providers and also by clarifying which of the tasks need to be considered better in the future projects.

Combining this kind of research with hectic industry IT outsourcing project with unpredictable phases and practitioners was recognized a challenge. The success depends strongly on the innate characteristics of the novice researchers of what they understand IS and action research (Estay-Niculcar and PastorCollado, 2002). While case study would have been another method to accomplish the targeted research in this project, more active role of research was anticipated and both practitioner's and researcher's roles were combined. Therefore action research method was chosen.

Case project data was collected during whole outsourcing project using authors' own plans, documents and notes. Research data as part of project documentation was also collected on continuous basis and analyzed per each checking point chronologically. This was conducted as part of the normal project practices. Every memorandum of the meetings which were held between supplier and customer were stored. The key documents were classified as (i) Request for Information (RFI), (ii) Request for Purchasing (RFP), (iii) Outsourcing agreement with describing Statements of Work (SOW), (iv) Service Level Agreements (SLA) and (v) project steering group materials.

Key research questions in the action research are focused on the following:

- What can practitioners do in ongoing project to improve the preparations for global outsourcing project?

- How key participants from customer side see the of selection criteria before and after the whole project?

\section{ANALYSIS}

\section{Case Description in the Research}

The case company in this research delivers large technology projects and related products and services globally and increasingly to emerging markets, where local infrastructure and IT services delivery is not highly matured. The case company is amongst leaders in those specific technologies and markets. The company has

Journal of Technology Management for Growing Economies, Volume 6, Number 2, October 2015
Significance of Supplier

Selection 
Hyvonen, $\mathrm{H}$. headquarter in Finland and turnover is more than $1 \mathrm{~b} €$ annually. The company Helminen, M. had not outsourced its IT operations in wider scale earlier and this project was Watanabe, C. the biggest outsourcing project in its history.

The IT infrastructure in scope was before hosted and managed mainly inhouse and hardware was quite old and subject to refreshment. The company's strategic actions target to global growth of the business in all of the continents and scalability and business continuity are required from IT. This case project was well aligned with company strategy execution plan. Total number of inhouse hosted servers in scope was more than 200.

In the middle of 2012, company was evaluated service delivery first for deeper globalization by continuing in-house server hosting mode or by outsourcing that. Driving forces were (i) data center was subject to relocation to new premises, and (ii) one new business model needed a global solution for their IT infrastructure. After several reviews, company's steering group decided to combine these two big changes and select a supplier, which could offer outsourced services for both objectives.

Based on thorough evaluation, Request for Information (RFI) was sent to nine large global ICT suppliers in November 2012. From the beginning, the scopes were focused on both corporate IT and business IT for specific part of the company's global service business. Thus, the outsourcing project consists of two main areas.

The company did an analysis to build a new data center for corporate IT (CorpIT) and those calculations and business case was existing for decision making. There was simultaneously need to build data center infrastructure for providing services in emerging global business model for company's one business unit for operate and maintenance type of business model (BusIT).

The great challenge with mentioned operate and maintain business model is that customer production sites are located in low infrastructure areas. Later on these type of IT delivery models are referred to CorpIT and BusIT. Target statement for the selection by the company Steering Group was: "To find one, truly global IT Infrastructure Service Provider to design, deploy and deliver all required Infra services and capacities, meeting expected Service Level Agreements with optimized Total Cost Ownership to enable and support business growth."

The scope of the research is to follow and analyze one outsourcing from preparation to the end of transition and transformation project.

\section{Supplier Selection Criteria}

Thorough list of requirements and basic information with the operate and maintain business unit were prepared. Request for Information (RFI) was sent to suppliers in November 2012 and Request for Proposal (RFP), was

Journal of Technology Management for Growing Economies, Volume 6, Number 2, October 2015 
sent in January 2013. While in the RFI phase, simple questions to shortlist (the number of potential suppliers from ten, nine to three) were focused, in the RFP phase after RFI phase included more detailed documentation of the technical requirements, timelines, environment description and service level requirements addressing to three selected candidates. The key measurements and success factors were (i) project schedule (servers transferred before June 2014), (ii) project cost (project budget inside $+/-5 \%$ ), and (iii) achieving scope related targets (agreed servers moved, ITIL processes implemented). No people related targets were defined.

Primary aim of the research was to find out how weight and emphasis of the vendor selection criteria will evolve from the project start compared to situation after project - post deployment. To evaluate vendors based on weights of selection criteria a spreadsheet that was created for evaluation of RFI responses was used. In the spreadsheet, the RFI responses were divided to six key categories: (i) Supplier Background (e.g., geographical presence in different market areas), (ii) Commercial Items (e.g., price breakdown), (iii) Key Descriptions (e.g., ITIL processes), (iv) Capacity (e.g., price for HW, SW and capacity availability), (v) Projects (e.g., capability to plan and implement projects), and (vi) Labor (e.g., personnel competences, price and availability). These categories included totally 61 questions or topics, which were ranked from 1 (poor) to 5 (excellent). Each category has a weight that influenced a lot in selection and was used in total vendor score calculation. Every supplier's responses were in the same form and were conducted a proper analysis what categories were emphasize mostly before handling responses. Five evaluation team members were organized to give weight from $1 \%$ to $100 \%$.

Scoring weights for selection (both BusIT and CorpIT) in the beginning of RFI were as tabulated in Table 1.

Table 1: The First Scoring for BusIT and CorpIT Outsourcing Supplier Selection (RFI phase)

\begin{tabular}{|l|c|}
\hline \multicolumn{1}{|c|}{ BusIT and CorpIT hosting evaluation RFI } & Total before (\%) \\
\hline Supplier background & 22.00 \\
\hline Key descriptions & 23.00 \\
\hline Commercial & 30.00 \\
\hline Capacity & 12.00 \\
\hline Projects & 8.00 \\
\hline Human labor & 5.00 \\
\hline Total & $\mathbf{1 0 0 . 0 0}$ \\
\hline
\end{tabular}

Journal of Technology Management for Growing Economies, Volume 6, Number 2, October 2015
Significance of Supplier

Selection 
Hyvonen, H. In the RFP phase, supplier's responses both from BusIT and CorpIT point of Helminen, M. view with diverse criteria weights were evaluated. This phase was more in Watanabe, C. detailed with 101 combined questions, where both BusIT and CorpIT were involved.

Tables 2 (BusIT) and 3 (CorpIT) tabulate the results.

Table 2: The Second Scoring for BusIT Outsourcing Supplier Selection (RFP phase)

\begin{tabular}{|l|c|}
\hline \multicolumn{1}{|c|}{ BusIT hosting evaluation RFP } & Total before (\%) \\
\hline Total Cost of Ownership / pricing & 27.00 \\
\hline Global coverage & 16.00 \\
\hline Change management & 13.00 \\
\hline General terms & 10.00 \\
\hline IT Service Management & 13.00 \\
\hline Governance & 13.00 \\
\hline Technical architecture and solution & 8.00 \\
\hline Total & 100.00 \\
\hline
\end{tabular}

Table 3: The Second Scoring for CorpIT Outsourcing Supplier Selection (RFP phase)

\begin{tabular}{|l|c|}
\hline \multicolumn{1}{|c|}{ CorpIT hosting evaluation RFP } & Total before (\%) \\
\hline Total Cost of Ownership / pricing & 18.00 \\
\hline CorpIT Data Center Specific Price & 16.00 \\
\hline Governance & 12.00 \\
\hline General terms & 10.00 \\
\hline IT Service Management & 16.00 \\
\hline Governance & 13.00 \\
\hline Technical architecture and solution & 12.00 \\
\hline Total & 100.00 \\
\hline
\end{tabular}

Based on those criteria used for vendor scoring, finally one supplier agreed with Letter of Intent (LOI) in April 2013 and started negotiations for agreement. 


\section{Project Execution}

Participants in the agreement negotiations from supplier included sales manager, account executive, pricing manager, technical architect and project manager 1. From customer side, the participants at this stage were contract owner, ICT manager, sourcing manager, EMEA region ICT head, external consultant who facilitated the agreement process in customer side, and occasionally manager representing business IT and sourcing lawyer. Negotiations took more than four months including summer vacations.

Even if RFP was well progressed, contractual items took long days before reaching defined and agreed stage. Customer's business IT part was under the pressure because operation and maintenance business unit had got an large order where it was needed IT services installation urgently. Here, the first issue cooperation with supplier was experienced. While account manager in supplier side made promises successively, they were not satisfied. Also there were plenty of open issues to be defined and decided on both sides regarding agreement. As a temporary solution separate document (Interim Agreement) was forced to conclude to get business IT request to proceed. The project progress should have been escalated with experience at that stage. After vacations, open topics were agreed thereby agreement was signed in the end of August 2013.

After the contract was signed, members of the supplier side team changed except account manager and original project managerl. When ramping up project for transition phase, project manager 1 continuously gave plenty of promises to improve structure of the project and its documentation. Despite several reminders and comments to account manager there were very little documentation except contractual items after several months. The actual project work was started but progress follow-up and actions planning were difficult as those were not well defined. This important phase in outsourcing process was not done well. The trust for vendor's abilities to execute was not created.

Customer was forced to wait five months after RFP agreement before there were first written draft level project plans in place. This led to a new situation when supplier's project managerl changed in August 2013. While a new project manager 2 responded taking customer's viewpoint what he could, it seemed that he was unable to get the rest of supplier organization to followup and commit to his plans. In addition, it looked like as if account manager was unable to support new project manager2 sufficiently. Both of the project managers did not have wider experience of truly global outsourcing cases. From customer side it was needed to follow up more thoroughly the progress and instruct what was needed to do. However, technical architecture work and
Significance of Supplier

Selection 
Hyvonen, $\mathrm{H}$. Helminen, $\mathrm{M}$. Watanabe, $\mathrm{C}$. partly ITIL processes planning and implementation progressed in sub teams despite of lacking structure for the whole project. One part of the delay in reaction was customer's limited experience on this kind of an outsourcing and expectations to delivery times.

In October the situation was analyzed within customer project team and realized that the estimated project deliverables were different than the weighting in RFI/RFP/Contract negotiation phases. Conclusion was that the importance of getting good and motivated people that had internal influence in the supplier onboard had not been highlighted enough. Prospect of the progress and coming success of the project were sincerely anxious about. The first meeting with supplier's Executive Sponsor and Account Executive was held in October 2013. From customer side the participants were contract owner, ICT manager and customer's executive sponsor. Supplier's executive sponsor promised to help but very little visible changes were recognized by customer. The next meeting with Executive Sponsor was held in December 2013. Finally, it was notified in that meeting that supplier's project manager 2 was going to be changed. Project manager3, who was going to join the project, was more experienced in leading global projects and not specialist in technical details.

A new project manager 3 who started his responsibility in December 2013 spent a lot of time to collaborate with customer's team members and started to create required documentation. It was noted that he created a lot of new documentation for project management, key documents and templates, and documentation format was changed again.

It was found that the new documentation was good and there were also a large number of participants in project's regular meetings. Cost estimates were provided thereby first reliance relationship was established in February 2014. The mutual trust started to emerge since then.

Customer had also brought new members in the project from the beginning of 2014, which brought customer side relationship management to better shape. Supplier resourced an assisting project manager in February 2014 to be responsible for coordinating infrastructure transfer activities, which dramatically speeded-up server moving. The main factor was better project management and follow up of several individual activities. These changes enabled moving forward by getting technical details agreed.

In March and April 2014 one supplier resource and internal project teams were arranged to sit physically in the same room. This resulted in good progress by letting the customer learn supplier's terminology and way of working. Thanks to these supportive actions project results were obtained.

In the beginning of 2014 governance structure, which was already agreed 
in RFP phase, was implemented. It took some time before it started work efficiently. During the most hectic time there was governance for 3 different phases: (i) contract negotiations, (ii) environment and process development, and (iii) deployment of the ongoing service. At that time organization and persons that were going to deliver ongoing services in the future had also became familiar. New people joined in the project to "Ongoing service" side and governance structure. Gradually regular meetings, documentation improvements, versioning, deployment project documentation and status updates started to bring visibility and overall understanding which led to results. It was found that trust started to win back when people started to work with less stress due to the change. When new people in the project learned and understood the start up works which were real needs and priorities in customer side, suddenly progress in excitable speed with project's activities increased teams motivation. This exact moment can be considered creative moment when new innovation suddenly emerges (Mori, 1997, Ishi, 2009).

Transition project reached overall targeted results well. Planned schedule was enabled to be kept except for the first business IT project which was delayed by four months. However, that was accepted because of customer's business reasons. Project spend went only $2 \%$ over target. Also project scope, server transfers and consolidations targets were reached well. Both global and local ICT services to operating and maintain business model also in emerging markets were enabled to implement.

In the planning phase, before the outsourcing project, five customer's key people in the process created a vendor selection list of criteria with weights. This list described which were outsourcing key success factors and the most important areas in Request For Information phase (10 suppliers). Two months and several presentations and evaluation sessions later similar list was made with different criteria to be used with a short list of suppliers (3 suppliers) in Request For Purchasing phase.

After the outsourcing transformation and transition project was finalized and ongoing service stabilized, same key participants were invited to reevaluate their scoring weights. They were instructed to use intuition and whole scale of experience collected in just ended project while answering.

\section{FINDINGS}

The action research outlined in the preceding Section was a quite a typical IT infrastructure outsourcing project from the project scope point of view. However, the geographical scope of the outsourcing agreement requires IT services deliverable to all continents with countries in different institutional systems (Watanabe, 2009). Thus, conceptualization of the IT outsourcing 
Hyvonen, $\mathrm{H}$. Helminen, M. Watanabe, $\mathrm{C}$. mechanism based on its elucidation is essential. This is the particularly the case for IT outsourcing to emerging economies.

Experiences of the action research were analyzed in this context with special attention to compare the implications of the change in the evaluation criteria for vendor selection before and after the project implementation.

The scope of the foregoing action research included some hundreds of servers, supplier candidates were big international IT suppliers. Experiences in confronting beyond anticipation issues have provided an expectation to be able to lead much easier project. Any organization that explores a new sourcing option in terms of new suppliers, new services, or new engagement models with existing suppliers, must plan on false starts and many mistakes (Lacity et al., 2008). While finally a successful outcome was obtained in the preceding experiences, learning exercise provides an expectation to a better position to evaluate how better results with less effort can be obtained. This is particularly important for IT outsourcing to emerging economies.

With such expectation, if we compare the scoring for BusIT and CorpIT outsourcing supplier selection at RFI phase before and after the project, we note the significant differences as compared in Table 4 . The largest increase in weights are for "Human Labor" $(+10.00)$ and "Projects" $(+7.00)$.

Table 4: Scoring after Project for both BusIT and CorpIT (RFI phase)

\begin{tabular}{|l|c|c|c|}
\hline BusIT \& Corp IT hosting RFI & Total before & Total after & Change \\
\hline Supplier background & 22.00 & 13.75 & -8.25 \\
\hline Key descriptions & 23.00 & 16.25 & -6.75 \\
\hline Commercial & 30.00 & 23.75 & -6.25 \\
\hline Capacity & 12.00 & 16.25 & 4.25 \\
\hline Projects & 8.00 & 15.00 & 7.00 \\
\hline Human Labor & 5.00 & 15.00 & 10.00 \\
\hline Total & 100.00 & 100.00 & 100.00 \\
\hline
\end{tabular}

Scores after the project suggest that outsourcing project execution was highly dependent on people involved in both sides. This fact was not ensured early enough in the beginning of the project. All in all five people in key positions were changed or left the project. Two of those were initiated by customer towards supplier and three people left project because they moved outside their company to other jobs.

Journal of Technology Management for Growing Economies, Volume 6, Number 2, October 2015 
Especially in starting the whole exercise, project management work, templates and tools were widely missing from selected vendors. This has to be clearly highlighted in the early phase during supplier evaluation. It is needed to be sure that supplier can execute project work efficiently. All the IT vendors that were part of the RFI have this capability. Client needs to ensure beforehand that selected vendor will utilize those in their project.

Contrary to these underestimation, "Supplier background" (-8.25) and "Key descriptions" (-6.75) were over weighted. Before RFI phase it was required to have high standards for the supplier's documentation. In addition, target was to choose a supplier which has basic elements for relationships and business management in good shape.

Similar comparison was conducted also in RFP phase. In RFP phase supplier was evaluated separately for BusIT and Corp IT. Table 5 compares the case for BusIT.

Table 5: Scoring after Project for BusIT (RFP phase)

\begin{tabular}{|l|c|c|c|}
\hline \multicolumn{1}{|c|}{ BusIT hosting evaluation RFP } & Total before & Total after & Change \\
\hline Total cost of ownership/pricing & 27.00 & 22.50 & -4.50 \\
\hline Global coverage & 16.00 & 12.50 & -3.50 \\
\hline Change management & 13.00 & 12.50 & -0.50 \\
\hline General terms & 10.00 & 8.75 & -1.25 \\
\hline IT Service management & 13.00 & 13.75 & 0.75 \\
\hline Governance & 13.00 & 15.00 & 2.00 \\
\hline Technical architecture and solution & 8.00 & 15.00 & 7.00 \\
\hline Total & $\mathbf{1 0 0 . 0 0}$ & $\mathbf{1 0 0 . 0 0}$ & $\mathbf{1 0 0 . 0 0}$ \\
\hline
\end{tabular}

Clearly we can now confirm that the importance of BusIT "Technical architecture and solution" (7.00) was underestimated. Building a global and local infrastructure simultaneously was a challenging task. In addition, "Governance" (2.00) required more focus than expected before the project. In Business IT RFP evaluation "Total Cost of Ownership/pricing” (-4.50) was focused higher before the project than after the project. In the longer run we are anyway quite sure, that cost efficiency will be important. Another criteria with lower weight was "Global coverage" (-3.50). This criterion was high before the project as it was required to find a supplier with global capabilities. It was found that all of the short-listed suppliers have capabilities to serve anticipated needs but their proposed way to deliver that varies.

Journal of Technology Management for Growing Economies, Volume 6, Number 2, October 2015
Significance of Supplier

Selection 
Hyvonen, $\mathrm{H}$.

Helminen, M.

Watanabe, $\mathrm{C}$.
Table 6 compares the case for CorpIT.

Table 6: Scoring after Project for CorpIT (RFP phase)

\begin{tabular}{|l|c|c|c|}
\hline CorpIT DC hosting evaluation RFP & Total before & Total after & Change \\
\hline IT service management & 16.00 & 10.00 & -6.00 \\
\hline CorpIT datacenter specific price & 16.00 & 11.25 & -4.75 \\
\hline Transition and transformation & 16.00 & 15.00 & -1.00 \\
\hline Governance & 12.00 & 12.50 & 0.50 \\
\hline General terms & 10.00 & 11.25 & 1.25 \\
\hline Technical architecture and solution & 12.00 & 16.25 & 4.25 \\
\hline Total cost of ownership/pricing & 18.00 & 23.75 & 5.75 \\
\hline Total & $\mathbf{1 0 0 . 0 0}$ & $\mathbf{1 0 0 . 0 0}$ & $\mathbf{1 0 0 . 0 0}$ \\
\hline
\end{tabular}

Evaluation for Corp IT showed that "Total cost of ownership/pricing" (5.75) and "Technical architecture and solution" (4.25) were considered more important after project more. The whole pricing for services in the outsourcing RFI-RFP-Contract was a challenging part of the project. For customer it was difficult to stay on track what was promised and to which price in RFP versus in contract's price letters. The additional price items were also raised up which were not listed up nor agreed on in RFP when comparison between suppliers was done. Technical architecture was also demanding after the project as there were plenty of technical details which it was needed to get solved when going live with project.

Before the project, all were very convinced that supplier needs to be strong with its process capabilities. Implementation of processes took time but went quite well. The next time it would not necessarily weight "IT service management" (-6.00) that high since there are always work for customer specific settings that need to be done. No matter how significant the processes are. In addition, we evaluated "CorpIT data center specific price" (-4.75) higher than after project. These criteria could have been combined with "Total cost of ownership/pricing" criteria as those specific prices were discussed with supplier in the same negotiations.

Whilst the beginning was difficult, at the end the results were good. In the beginning it was trusted that the supplier will lead project with well developed practices and tools, with skilled and motivated people but reality was something different. Especially after the first half of the project duration, the executive sponsor was escalated when it was found something was wrong. In addition, more thorough following was endeavored that there was well

Journal of Technology Management for Growing Economies, Volume 6, Number 2, October 2015 
documented plans and project governance was in place. Customer has also some responsible of the outcome.

When right people in the project on both sides were obtained, works were started to make progress. It can be concluded that with proper documentation and project plans, the target was attained much easier. Also better plans made are easier for customer to avoid rlsource shortages, which were experienced in March-April time. Even though it can be considered to have selected a correct vendor, or at least good enough at the moment, some self study is in place.

During the long transition and transformation project implementation should have stopped several times and really evaluated the progress of the project. Time could have shortened thereby certain activities took and in a way helped supplier/provider to get things finalized earlier. This help would require an active role of the customer as well to get things done. On the other hand this statement is in conflict with the idea of buying outsourcing services from a vendor. It could be that this is not achievable at least when outsourcing would mean jobs to be fled to offshore site. In the end this transformation phase and coming change management process will be key topics when evaluating success of whole vendor relation scope. The proposed evaluation in the critical phase of the project should be based on the same criteria that were used in the scoring. Purpose of this evaluation should be:

- Are we getting what we wanted?

- Are we doing our share to ensure the outcome?

- What changes or corrective actions should be performed?

However, with revised criteria weights and checked scoring it would still end up selecting the same vendor. This indicates that there is no perfect match in IT outsourcing, just close enough and a lot of work to make it succeed. In the end it is customer who is building the outsourcing results to its own benefits. Literature describes many scenarios where persons in client side consider outsourcing company as a threat which effects working moral (Taylor, 2007).

To summarize the key findings and learning it can be concluded that in this case that changing to right type of project manager would have impacted to better and faster progress in the project. When right people both from supplier and customer side learned a common way to work for common goals, very rapid progress in project tasks was attained.

According to these findings, especially in the beginning of the project "global coverage" was overestimated. It can be concluded that this is partly paradox because implementation of outsourced services will happen in very different markets. After project it can be seen, that delivering ICT services is at the first place depending on how well supplier's key account and service

Journal of Technology Management for Growing Economies, Volume 6, Number 2, October 2015
Significance of Supplier

Selection 
Hyvonen, $\mathrm{H}$. people build up processes and capabilities. When those are in place, required Helminen, M. services can be delivered accordingly also to company's needs in emerging Watanabe, C. markets.

\section{IMPLICATIONS TO OUTSOURCING TO EMERGING ECONOMIES}

In outsourcing projects to complex environments particularly to emerging markets, it was demonstrated that action research offers much better insight to researchers. Given the increasing significance of IT outsourcing to emerging economies, intensive action research should be encouraged for conceptualization of outsourcing mechanism.

Foregoing research suggests that the project or activities where researchers are actually involved with certain duration would be suitable. It is advisable that a project with duration of about 1 year is good to make required analysis and findings. Preceding experiences suggest that majority of the improvements efforts should focus on "labor/people" category. Need to create solid project teams with comprehensive collaboration, management support, enough project allocated time and global governance on both sides should not be underestimated. Furthermore, it should be reminded that it is quite common that people will be changed in project roles. The cultural things are often very complex and difficult to understand because it encompasses a wider range of behavioral territory than other studied organization capital issues (Kaplan and Norton, 2004). It was experienced that traditional Finnish originated culture met American IT giant with its processes and way to operate with people's mindset suggesting closer culture match will make things easier. However, increasing significance of IT outsourcing to emerging economies necessitates difficult tasks: matching with heterogeneous culture. In this context, sustainable efforts in conceptualization of ICT outsourcing mechanism play decisive role for adapting to institutional systems in both supplier and customer side thereby co-evolutional dynamism between supplier and customer can be expected as a consequence of outsourcing to emerging economies.

Final success in preceding project can be attributed to this co-evolution. It was demonstrated that the better the combination of technical skills and project management competences, the better a result can be. It was also demonstrated that trust can be created only by working with facts and keeping promises i.e., create documentation, which is required. Also documenting plans and agreed items are necessary for a common language. This creates more transaction costs especially in the beginning but is absolutely needed to ensure progress without continuous escalations and need to find out what has been written in contracts.

Journal of Technology Management for Growing Economies, Volume 6, Number 2, October 2015 
Even though the preceding challenges confronted unexpected difficulties beyond anticipation during the project implementation, it can be strongly recommend that opening up the project key success factors to counterparts in outsourcing game, particularly to those in emerging economies.

Noteworthy key success factors include significant impacts of managers change notwithstanding common practice, experience of creative moment emerged when trust restarted by new people learned and understood setup works thereby people started to work with less stress, and global coverage was overestimated contrary to underestimation of human factors.

\section{CONCLUSION}

In line with the increasing significance of the acceleration of IT advancement and also of harnessing the vigor of emerging economies, IT outsourcing to emerging economies has become global concerns. Expanding business areas to emerging markets enables global companies to enjoy a critical competitive edge by choosing the best option in outsourcing strategy and supplier selection. Consequently, outsourcing partner selection criteria have become critical issues for both supplier and customer.

This paper attempted to provide insightful suggestions to these issues. An empirical analysis was conducted taking supplier selection criteria evolvement in global IT outsourcing project focusing on action research in a multinational company.

Noteworthy findings include:

(i) Significant impacts of managers change during the course of project implementation notwithstanding common practice,

(ii) Emergence of creative moment when trust won back by new people learned and understood setup works thereby all people involved started to work with less stress, and

(iii) In suppliers selection criteria, weighting of global coverage was overestimated contrary to underestimation of human factors.

These findings provide following policy suggestions suggestive to companies IT outsourcing:

(i) Sustainable efforts in conceptualization of IT outsourcing mechanism should be endeavored,

(ii) In-depth understanding of institutional systems in emerging economies should be further endeavored, and

(iii) Optimal resources allocation in both supplier and customer so as to satisfy condition for creative moment.

Journal of Technology Management for Growing Economies, Volume 6, Number 2, October 2015
Significance of Supplier

Selection 
Hyvonen, H. In order to complement the weakness of this research based on one Helminen, M. example initiated by Finland multinational company, further work Watanabe, C. should focus similar action research taking other companies initiatives.

\section{REFERENCES}

Avison, D., Lau, F., Myers, M. and Nielsen, P. (1999). 'Action Research'. Communications of the ACM, 42:1, pp. 94-97. http://dx.doi.org/10.1145/291469.291479.

Chou, D.C., and Chou, A.Y. (2009) 'Information Systems Outsourcing Life Cycle and Risks Analysis'. Computer Standards and Interfaces, 31:5, pp. 1036-1043. http://dx.doi.org/ 10.1049/iet-sen.2013.0013

Dibbern J., Goles T., Hirschheim R., \& Jayatilaka B. (2004) 'Information Systems Outsourcing: A Survey and Analysis of the Literature'. The DATA BASE for Advances in Information Systems, 35:4, pp. 6-102. http://dx.doi.org/10.1145/1035233.1035236.

Estay-Niculcar,C. and Pastor-Collado, J. (2002) 'A Maturity Model for Information Systems Action-Research Project Management', Proceeding, ECIS 2002 June 6-8, Gdańsk, Poland.

Graf, M., and Mudambi, S. M. (2005) 'The Outsourcing of IT-enabled Business Processes: A Conceptual Model of the Location Decision', Journal of International Management, 11:2, pp. 253-268.

Grossler, A., Laugen, B.T., Arkader, R. and Fleury, A. (2013) 'Differences in Outsourcing Strategies between Firms in Emerging and in Developed Markets', International Journal of Operations and Production Management, 33:3, pp.296-321.

Hätönen, J. (2005) 'Managing the Process of Outsourcing - Examining the Process of Outsourcing Product-development Activities in Software Firms'. Dissertation. University of Turku School of Economics.

Hofstede, G. (1991). 'Cultures and Organizations,' London, McGraw-Hill International.

Ishi, J. (2009). 'Business Insight.' Tokyo, Iwanami Shoten Publishers ( in Japanese).

Javalgi, R.G., Dixit, A. and Scherer. (2009) 'Outsourcing to Emerging Markets: Theoretical Perspectives and Policy Implications', Journal of International Management, 15:1, pp. 156-168.

Kaplan, R.S., and Norton, D.P. (2004). 'Strategy Maps: Converting Intangible Assets into Tangible Outcomes', Boston, MA, Harvard Business School Press.

KPMG State-of-Outsourcing (2014). https://www.kpmginstitutes.com/content/dam/kpmg/ sharedservicesoutsourcinginstitute/pdf/2014/state-of-outsourcing-2014-exec-findings-hfs. pdf, KPMG Research.

Lacity, M., and Hirschheim, R. (1993). 'Information Systems Outsourcing; Myths, Metaphors, and Realities'. England, John Wiley \& Sons, Inc..

Lacity M., and Willcocks L. (1998) 'An Empirical Investigation of Information Technology Sourcing Practices: Lessons from Experience'. MIS Quarterly, pp. http://dx.doi.org/363408. $10.2307 / 249670$.

Lacity, M., Willcocks, L. and Rottman, J. (2008) 'Global Outsourcing of Back Office Services: Lessons, Trends and Enduring Challenges', Strategic Outsourcing: An International Journal, 1:1, pp. 13-34.

Lacity, M., Khan, S. and Willcocks, L. (2009) 'A Review of the IT Outsourcing Literature: Insights for Practice'. Journal of Strategic Information Systems, 18: 3, pp. http://dx.doi. org/130-146. 10.1016/j.jsis.2009.06.002.

Lee, J.N. and Kim, Y.G. (1999) 'Effect of Partnership Quality on IS Outsourcing Success: Conceptual Framework and Empirical Validation'. Journal of Management Information Systems, pp. 29-61.

Levina, N., and Ross, J.W. (2003) 'From the Vendor's Perspective: Exploring the Value

Journal of Technology Management for Growing Economies, Volume 6, Number 2, October 2015 
Proposition in Information Technology Outsourcing', MIS Quarterly 27:3, pp. 331-364.

Mori, T. (1997) 'Recalling Future' Contemporary Philosophy, 25:12, pp. 96-101(in Japanese).

Palugod, N., and Palugod, P. (2011) 'Global Trends in Offshoring and Outsourcing, International Journal of Business and Social Science, 2:16, pp. 13-19.

Prahalad, C.K. (2004)'The Fortune at the Bottom of the Pyramid: Eradicating Poverty through Profits', New Jersey, Wharton School Publishing.

Rottman J., and Lacity, M. (2006) 'Proven Practices for Effectively Offshoring IT Work', Sloan Management Review, 47: 3, pp. 56 - 63.

Simonsen, J. (2009). 'A Concern for Engaged Scholarship: The challenges for action research projects', Scandinavian Journal of Information Systems, 21: 2, Article 1.

Taylor, H. (2007) 'Outsourced IT Projects from the Vendor Perspective: Different Goals, Different risks'. Journal of Global Information Management, 15: 2, pp. 1-27.

The CIO Insight. (2012) http://www.cioinsight.com/c/a/Outsourcing/ IT-Outsourcing-DealsGone -Bad-851734/ 1.

Teng, J. T. C., M. J. Cheon, \& V. Grover. (1995) 'Decisions to Outsource Information Systems Functions: Testing a Strategy-Theoretic Discrepancy Model', Decision Sciences, 26:1, pp. 75-103. http://dx.doi.org/10.1111/j.1540-5915.1995.tb00838.x.

Vagadia, B. (2012) 'Strategic Outsourcing Management for Professionals', Berlin, Springer -Verlag.

Watanabe, C. (2009) 'Managing Innovation in Japan: The Role Institutions Play in Helping or Hindering How Companies Develop Technology'. Berlin, Springer. http://dx.doi. org/10.1007/978-3-540-89272-4.

Watanabe, C., Naveed, K. and Zhao, W. (2014) 'Institutional Sources of Resilience in ICT Global Leaders: Harnes the Vigor of Emerging Power'. Journal of Technology Management for Growing Economies, 5:1, pp. 7-34.

Zhao, W. and Watanabe, C. (2010) 'Risk Management in Software Outsourcing: A Portfolio Analysis of India's Case based on Software Export Market Constitution'. Journal of Services Research, 10:1, pp. 143-155.

Zhao, W., Watanabe, C. and Tou, Y. (2013) 'Co-emergence of Institutional Innovation Navigates the New Normal in Growing Economies.' Journal of Technology Management for Growing Economies, 4:1, pp. 69-81.
Significance of Supplier

Selection

Journal of Technology Management for Growing Economies, Volume 6, Number 2, October 2015 